\title{
STRATEGI PENGEMBANGAN PARIWISATA MELALUI DESA WISATA DI KABUPATEN TIMOR TENGAH SELATAN UNTUK MENINGKATKAN JUMLAH PERGERAKAN WISATAWAN
}

\author{
Sari Bandaso Tandilino, SE., MM \\ Jurusan Pariwisata, Politeknik Negeri Kupang \\ Jl. Adisucipto Kampus Penfui-Kupang NTT \\ E-mail: saribandaso@yahoo.co.id
}

\begin{abstract}
Abstrak
Provinsi NTT memiliki 1.192 pulau yang tersebar di 22 kabupaten dan kota dan jumlah desa sebanyak 2.924 merupakan peluang dalam melakukan pengembangan pariwisata pedesaan. Visi dan misi pemerintah provinsi Nusa Tenggara Timur (NTT) menargetkan pada tahun 2018 memiliki 273 desa wisata yang tersebar di 22 kabupaten/kota .Hingga tahun 2013, NTT sudah memiliki 73 desa wisata, tetapi sesuai dengan program Gubernur NTT , jumlah desa wisata ini akan ditingkatkan menjadi 273 desa selama tahun 2013-2018 menuju pencapaian target menjadikan NTT salah satu destinasi pariwisata dunia 2018. Berdasarkan hasil perhitungan ImportancePerformance Analysis maka dari tingkat kesesuaian diatas diperoleh nilai kesesuaian antara penilaian kepentingan dan harapan wisatawan terhadap kualitas obyek daerah tujuan wisata di Kecamatan Fatumnasi sebesar $77 \%$. Hal ini berarti bahwa persepsi atau penilaian wisatawan termasuk dalam kriteria puas. Berdasarkan hasil diagram kartesius kondisi jalan berada dalam kuadran I , atraksi wisata alam, wisata budaya, buatan manusia , sarana transportasi , rambu lokasi wisata dan homestay dalam kuadran II , mutu pelayanan amenitas, tourist information center, dan kios souvenir berada kuadran III , dan atribut kelompok sadar wisata (Pokdarwis) berada dalam kuadran IV.
\end{abstract}

Keywords : Strategi, Pariwisata, Model, Desa Wisata, Wisatawan

\section{PENDAHULUAN}

\subsection{Latar Belakang}

Dengan tagline New Tourism Territory (NTT), daerah ini sedang berbenah untuk menjadikan Nusa Tenggara Timur sebagai gerbang selatan pariwisata Indonesia yang meliputi Australia dan Pasifik. Untuk itu berbagai upaya telah dilakukan pemerintah seperti penetapan event core, major dan supporting termasuk didalamnya pengembangan desa wisata dengan menargetkan kunjungan wisatawan sebanyak 600.000 orang dari target nasional 20 juta wisatawan selama tahun 2015 .Provinsi NTT memiliki 1.192 pulau yang tersebar di 22 kabupaten dan kota dengan jumlah desa sebanyak 2.954 desa merupakan peluang dalam melakukan pengembangan pariwisata pedesaan. Hal ini sesuai visi dan misi pemerintah provinsi Nusa Tenggara Timur (NTT) yang menargetkan pada tahun 2018 memiliki 273 desa wisata yang tersebar di 22 kabupaten/kota di provinsi kepulauan itu. Hingga tahun 2013, NTT sudah memiliki 73 desa wisata, tetapi sesuai dengan program Pemda NTT ,jumlah desa wisata ini akan ditingkatkan menjadi 273 desa selama tahun 2013-2018 menuju pencapaian target menjadikan NTT salah satu destinasi pariwisata dunia 2018. Sehingga konsep pembangunan kepariwisataan di wilayah ini harus berbasis masyarakat. Dalam kaitan dengan ini, pengembangan desa wisata harus menjadi wahana untuk melatih kreasi masyarakat dalam menghadapi denyut nadi kehidupan pariwisata di daerahnya masingmasing. Upaya itu dicetuskan agar masyarakat dapat menikmati hasil dari pengembangan sektor unggulan tersebut. Masyarakat harus menjadi subjek pembangunan dari sektor pariwisata itu sendiri. Mereka harus disiapkan dengan baik, seperti bagaimana membuat barang-barang souvenir, kuliner dan lain-lain bagi kepentingan wisatawan . Hal ini sesuai 8 poin agenda pembangunan prioritas yang tertuang dalam RPJMD provinsi NTT tahun 2013 - 2018 .Seiring dengan hal tersebut, arah dan kebijakan pembangunan Kabupaten Timor Tengah Selatan menempatkan pariwisata sebagai sektor penggerak dan perekonomian masyarakat yang dapat memberikan kontribusi signifikansi bagi peningkatan kesejahteraan rakyat yang dikemas melalui berbagai konsep dan pendekatan seperti pariwisata berkelanjutan (sustainable tourism development) dan pariwisata berbasis 
kerakyatan (community based tourism) yang semuanya mendukung pengembangan desa wisata. Hal ini dapat menunjang program pengentasan kemiskinan dimana $27,4 \%$ penduduk Kabupaten TTS masih tergolong miskin (bpstts,2015).

Kecamatan Fatumnasi Kabupaten Timor Tengah Selatan merupakan salah satu dari 32 kecamatan yang memiliki populasi penduduk sebanyak 6.869 jiwa yang memiliki 5 desa , 13 dusun , $30 \mathrm{RW}$ dan $61 \mathrm{RT}$ dan luas wilayah luas wilayah 194,658 $\mathrm{Km}^{2}$. Secara geografis kecamatan Fatumnasi berada diketinggian 1200-1800 dpl. Secara geonologis wilayah Kecamatan Fatumnasi arah utara berbatasan dengan Kabupaten TTU, arah selatan berbatasan dengan kecamatan Mollo Utara, arah timur dengan Kecamatan Tobudan arah barat dengan kecamatan Nunbena dan Kabupaten Kupang.

Situasi masyarakat desa di kecamatan Fatumnasi Kabupaten TTS memiliki keunikan dimana seluruh anggota masyarakat memiliki keterkaitan kerabat satu dengan lainnya. Sistem kekerabatan yang erat masih terjaga oleh sebab seluruh anggota masih teguh memilihara adat istiadat. Pola kekerabatan inilah yang dijadikan dasar hubungan kemasyarakat termasuk kepada pendatang sehingga penduduk desa menganggap pendatang seperti saudara yang pulang kampung. Hal ini dimungkinkan mengingat sebagian besar angkatan kerja desa pergi merantau di kota besar. Keterbukaan yang ditampilkan masyarakat tersebut merupakan prasyarat dasar pelayanan prima. Sejalan dengan itu , maka desa di kecamatan Fatumnasi bisa diarahkan kepada pengembangan Desa Wisata yang didasari dengan pendekatan sustainable tourism development, community approach, village tourism, dan ecotourism. Ramuan utama desa wisata diwujudkan dalam gaya hidup dan kualitas hidup masyarakatnya. Keaslian juga dipengaruhi keadaan ekonomi, fisik dan sosial daerah pedesaan tersebut, misalnya ruang, warisan budaya, kegiatan pertanian, bentangan alam, jasa, pariwisata sejarah dan budaya, serta pengalaman yang unik dan eksotis khas daerah. Dengan demikian, pemodelan desa wisata harus terus dan secara kreatif mengembangkan identitas atau ciri khas daerah. Akan tetapi, kondisi potensi pariwisata yang ada di desa-desa kabupaten TTS belum dikelola secara maksimal, hal ini lebih disebabkan oleh keterbatasan sumber daya manusia pariwisata di desa-desa, kondisi masyarakat desa yang belum sepenuhnya mengerti akan arti penting pariwisata terutama desa wisata, minimnya perhatian swasta yang berkiprah di bidang usaha jasa dan sarana pariwisata di desa disertai dengan rendahnya tingkat pendidikan masyarakat desa yang berimplikasi pada kurang responnya masyarakat terhadap inovasi bidang pariwisata yang masuk, Disamping itu pula belum adanya arahan pengembangan serta strategi pengembangan kegiatan pariwisata yang berbasis kepada kearifan lokal masyarakat Desa Wisata dari PEMDA kabupaten TTS . Kenyataan ini dapat terihat di desa- desa di wilayah Kabupaten Timor Tengah Selatan dimana potensi-potensi pariwisata yang ada dibiarkan begitu saja dan hanya dijadikan sebagai simbol-simbol sejarah saja. Berdasarkan uraian latar belakang diatas, maka penulis tertarik mengadakan penelitian tentang Strategi Pengembangan Pariwisata melalui Model Desa Wisata di Kabupaten Timor Tengah Selatan untuk Meningkatkan Jumlah Pergerakan Wisatawan.

\subsection{Perumusan Masalah}

Dengan latar belakang yang telah diuraikan di atas maka perumusan masalah dalam penelitian ini adalah

1. Bagaimana nilai-nilai strategis kepariwisataan yang dimilki Kecamatan Fatumnasi Kabupaten TTS sebagai destinasi penerapan model desa wisata.

2. Bagaimana identifikasi lingkungan internal dan eksternal yang mempengaruhi pemerintah Kabupaten TTS dalam mengembangkan Desa Wisata di Kecamatan Fatumnasi.

3. Bagaimana model strategi pengembangan Desa Wisata di Kecamatan Fatumnasi Kabupaten TTS.

\subsection{Tujuan Penelitian}

1. Untuk mengetahui nilai-nilai strategis kepariwisataan yang dimiliki Kecamatan fatumnasi Kabupaten TTS sebagai destinasi penerapan model desa wisata.

2. Untuk mengetahui identifikasi lingkungan internal dan eksternal yang mempengaruhi pemerintah Kecamatan Fatumnasi Kabupaten TTS dalam mengembangkan Desa Wisata.

3. Untuk menyusun model strategi pengembangan Desa Wisata di Kecamatan Fatumnasi Kabupaten TTS .

\subsection{Manfaat Penelitian}

1. Manfaat secara teoritis

a. Sebagai sumbangan teoritis terhadap ilmu pengetahuan ,khususnya yang berhubungan dengan manajemen strategi pariwisata dan penrepan desa wisata 
b. Sebagai bahan referensi bagi pihakpihak yang akan melaksanakan penelitian lebih lanjut.

1. Manfaat praktis

c. Sebagai sumbangan pemikiran bagi Pemda Kabupaten Timor Tengah Selatan dalam penerapan pemberdayaan masyarakat melalui program Desa Wisata di Kecamatan Fatumnasi

d. Sebagai penambah angka kredit bagi dosen

\section{TINJAUAN PUSTAKA}

\subsection{Strategi Pengembangan Pariwisata}

Strategi merupakan sejumlah keputusan dan aksi yang ditujukan untuk mencapai tujuan (goal) dan menyesuaikan sumber daya organisasi dengan peluang dan tatangan yang dihadapi dalam lingkungan industrinya (Coulter, 2002: 7 dalam Kuncoro,2005: 12).

a. Proses Manajemen Strategis

Manajemen strategi sebagai suatu proses meliputi sejumlah tahapan yang saling berkaitan dan berurutan. Tahapan utama proses manajemen strategi, dan evaluasi kinerja menurut Pearce \& Robbins,(2003:1116) dalam Kuncoro (2005: 13) yaitu :

a) Analisis lingkungan, meliputi deteksi dan evaluasi konteks organisasi, lingkungan eksternal dan internal organisasi

b) Formulasi strategi, mencakup desain dan pilihan strategi yang sesuai.

c) Implementasi strategi, adalah prosses bagaimana melaksanakan strategi yang telah diformulasikan dengan tindakan nyata.

d) Evaluasi strategi, adalah proses mengevaluasi bagaimana strategi diimplementasikan dan sejauh mana mempengaruhi kinerja.

\section{b. Perumusan strategi}

Perumusan strategi adalah pengembangan rencana panjang untuk manajemen efektif dari kesempatan dan ancaman lingkungan, dilihat dari kekuatan dan kelemahan organisasi. Perumusan strategi meliputi menentukan misi organisasi, menentukan tujuan-tujuan yang ingi dicapai, pengembangan strategi dan penetapan pedoman kebijakan.(J. David Hunger \& Thomas L. Wheelen, 2003: 12)

c. Implementasi strategi

Implementasi strategi (J. David Hunger \& Thomas L. Wheelen, 2003:17) adalah proses dimana manajemen mewujudkan strategi dan kebijaksanaan dalam tindakan melalui pegembangan program, anggaran, dan prosedur. Proses tersebut meliputi perubahan budaya secara menyeluruh, struktur dan atau system manajemen dari organisasi secara keseluruhan. Sebagai perencanaan operasional, implementasi strategi sering melibatkan keputusan sehari-hari dalam alokasi sumber daya.

\section{d. Evaluasi dan pengendalian}

Evaluasi dan pengendalian (J. David Hunger \& Thomas L. Wheelen, 2003:19) adalah proses yang melaluinya aktivitasaktivitas organisasi dan hasil kerja dimonitor dan kinerja sesungguhny dibandingkan dengan kinerja yang diinginkan. Walaupun evaluasi dan pengendalian merupakan elemen akhir yang utama dari manajemen strategis, elemen itu juga dapat menunjukkan secara tepat kelemahan-kelemahan dalam implementasi strategi sebelumnya dan mendorong proses keseluruhannya untuk dimulai kembali.

Berdasarkan analisis SWOT, dapat diformulasikan strateginya dengan cara (Rangkuti, 2006) :

1) menentukan faktor-faktor strategis eksternal;

2) menentukan faktor-faktor strategis internal;

3) merumuskan alternatif strategi dengan alat bantu Space Matrix dan Matrix SWOT

e. Perumusan Strategi Pengembangan Pariwisata

Strategi pengembangan keparriwisataan bertujuan untuk mengembangkan produk dan pelayanan yang berkualitas, seimbang, dan bertahap. Langkah pokok dalam strategi pengembangan kepariwisataan (Suwantoro, $2004: 55)$

a) Dalam jangka pendek dititikberatkan pada optimasi, terutama untuk : mempertajam dan memantapkan citra kepariwisataan, meningkatkan mutu tenaga kerja, meningkatkan mutu pengelolaan, memanfaatkan produk yang ada, memperbesar saham dari pasar pariwisata yang telah ada

b) Dalam jangka menengah dititik-beratkan pada konsolidasi, terutama dalam: Memantapkan cara-cara kepariwisataan , mengkonsollidasikan kemampuan pengelolaan, mengembangkan dan diversifikasi produk, mengembangkan jumlah dan mutu tenaga kerja

c) Dalam jangka panjang dititik-beratkan pada pengembangan dan penyebaran dalam: Pengembangan kemampuan pengelolaan, pengembangan dan penyebaran produk dan pelayanan, pengembangan pasar pariwisata baru, pengembangan mutu dan jumlah tenaga kerja. 
Menurut Getz (1987:93) dan Page (1995) terdapat lima pendekatan dalam mengembangkan pariwisata, antara lain:

1. Bossterm yaitu: suatu pendekatan sederhana yang melihat pariwisata sebagai suatu atribut positif untuk suatu tempat dan penghuninya. Namun masyarakat setempat tidak dilibatkan dalam proses perencanaan dan daya dukung wilayah tidak dipertimbangkan secara matang.

2. The economic-industry approach (pendekatan ekonomi-industri) yaitu: pendekatan pengembangan pariwisata yang tujuan ekonominya lebih didahulukan dari tujuan social dan lingkungan dan menjadikan pengalaman pengunjung dan tingkat kepuasan sebagai sasaran utama.

3. The physical-spatial approach (pendekatan fisik-keruangan), yaitu: pendekatan ini didasarkan pada tradisi penggunaan lahan geografis.Strategi pengembangannya berdasarkan perencanaan yang berbedabeda melalui prinsip-prinsip keruangan (spatial). Misalnya pengelompokan pengunjung di satu kawasan dan pemecahan-pemecahan tersebut untuk menghindari kemungkinan terjadinya konflik. Hanya saja kekurangan dari pendekatan ini adalah kurang mempertimbangkan dampak sosial dan kultur dari pengembangan wisata.

4. The community approach (pendekatan kerakyatan), yaitu: pendekatan ini lebih menekankan pada pentingnya keterlibatan maksimal dari masyarakat setempat di dalam proses pengembangan pariwisata. Pendekatan ini menganggap pentingnya suatu pedoman pengembangan pariwisata yang dapat diterima secara sosial (socially acceptable). Pendekatan yang dilakukan adalah menekankan pentingnya manfaat sosial dan cultural bagi masyarakat lokal secara bersamasama termasuk di dalamnya pertimbangan ekonomi dan lingkungan.

5. Sustainable approach (pendekatan keberlanjutan), yaitu: pendekatan berkelanjutan dan berkepentingan atas masa depan yang panjang serta atas sumber daya dan efek-efek pembangunan ekonomi pada lingkungan yang mengkin menyebabkan gangguan cultural dan sosial yang memantapkan pola-pola kehidupan dan gaya hidup individual.

\subsection{Desa Wisata}

Desa wisata adalah suatu bentuk integrasi antara atraksi, akomodasi dan fasilitas pendukung yang disajikan dalam suatu struktur kehidupan masyarakat yang menyatu dengan tata cara dan tradisi yang berlaku. (Permenbudpar

PM.No.26/UM.001/MKP/2010).

\subsection{Pendekatan Pengembangan Pariwisata Pedesaan}

Pendekatan yang digunakan dalam pengembangan model pariwisata perdesaan yaitu Integrated Rural Tourism (IRT) atau pendekatan pariwisata perdesaan terpadu yang harus dapat;

1) Memanfaatkan dengan optimal sumber daya alam, ekonomi, dan sosial budaya lokal, sekaligus memberikan perlindungan terhadap keberlanjutan sumber daya tersebut.

2) Memberdayakan masyarakat lokal pada setiap tahap pengembangan pariwisata perdesaan

3) Mendorong terwujudnya keterkaitan antarsektor dalam pengembangan pariwisata perdesaan

4) Membuka peluang dan menciptakan iklim yang kondusif bagi pembentukan kemitraan/kolaborasi antar pihak-pihak yang terkait dengan pengembangan pariwisata perdesaan

5) Memberikan manfaat yang luas, tidak hanya kepada masyarakat dan sumber daya lokal, tetapi juga kepada sistem perdesaan yang lebih luas (Puslitbang Kemenperaf, 2008) .

Adapun karakteristik kegiatan pariwisata pedesaan dapat dibagi dalam tiga kelompok (Puslitbang Kemenperaf, 2008), yaitu:

a) Interaksi penuh yaitu model pengembangan desa wisata yang memungkinkan wisatawan berinteraksi penuh dengan kehidupan dan budaya masyarakat pedesaan secara utuh. Wisatawan dimungkinkan untuk tinggal bermalam di akomodasi yang disiapkan oleh desa tersebut .

b) Interaksi semi penuh yaitu bentuk-bentuk one way trip yang dilakukan oleh wisatawan, kegiatan-kegiatan meliputi makan dan berkegiatan bersama penduduk dan kemudian wisatawan dapat kembali ke tempat akomodasinya.

c) Tanpa interaksi yaitu wisatawan hanya melakukan interaksi yang terbatas dengan kehidupan masyarakat desa dan bersifat pasif.

\section{METODE PENELITIAN}

\subsection{Lokasi Penelitian}

Lokasi penelitian ditetapkan secara purposive di Desa Fatumnasi Kecamatan Fatumnasi Kabupaten Timor Tengah Selatan. 
3.2 Teknik Pengumpulan Data

\subsubsection{Kuesioner}

1) Kuesioner untuk masyarakat , dimaksudkan untuk memperoleh informasi secara tertulis dari responden tentang sikap masyarakat Desa Fatumnasi Kecamatan Fatumnasi tentang rencana pengembangan desa wisata sesuai dengan unsur-unsur Sapta Pesona ( Aman, Tertib, Bersih, Sejuk, Indah , Ramah dan Kenangan) .

2) Kuesioner untuk wisatawan nusantara dan mancanegara, dengan menggunakan Importance-Performance Analysis untuk memetakan hubungan antara kepentingan dengan kinerja dari masing-masing atribut yang ditawarkan dan kesenjangan antara kinerja dengan harapan dari atribut-atribut tersebut atau untuk mengetahui rasio antara harapan dan kinerja kualitas ODTW yang dilaksanakan pada Desa Fatumnasi, Nenas, Nuapain, Kuanoel dan Mutis di Kecamatan Fatumnasi Kabupaten TTS.

\subsubsection{Wawancara}

Merupakan cara memperoleh informasi melalui data dengan jalan mengadakan tanya jawab langsung antara peneliti dengan pihakpihak yang dapat membantu memberikan informasi tambahan. Dalam tahap wawancara ini digunakan formulir Testimoni Analisa SWOT

\subsubsection{Focus Group Discussion (FGD)}

Merupakan cara memperoleh informasi dengan jalan mengadakan pertemuan dan sekaligus berdiskusi tentang strategis pengembangan desa wisata di Desa fatumnasi Kecamatan Fatumnasi Kabupaten TTS dengan memberikan formulir-formulir :

a) Formulir Pengembangan Destinasi Wisata yaitu formulir yang menguraikan potensipotensi yang dimiliki oleh destinasi di Kecamatan Fatumnasi Kabupaten TTS yang sesuai dengan konsep 4A yaitu tersedianya Attraksi, Aksesibilitas, Amenities dan Ancillararies.

b) Formulir Identifikasi Masalah sesuai dengan unsur-unsur Sapta Pesona serta penyusunan program dan kegiatan pada masyarakat di Desa Fatumnasi kecamatan Fatumnasi

c) Formulir Daftar Usaha Masyarakat yang sedang beroperasi dalam menunjang pengembangan destinasi di Desa Fatumnasi Kecamatan Fatumnasi

d) Formulir Testimoni Analisa SWOT

\subsubsection{Studi Dokumen}

Merupakan cara memperoleh informasi dengan jalan mempelajari sumber data tertilis untuk memperoleh data sekunder mengenai sejarah organisasi, jumlah dosen, lokasi, status kepegawaian, jabatan fungsional dan data tertulis lainnya yang berkaitan dengan penelitian.

\subsection{Jenis dan Sumber Data}

a. Data Primer yaitu data yang diperoleh dari jawaban yang diberikan responden melalui quisioner dan wawancara langsung dengan Dinas Kebudayaan \& Pariwisata, BAPPEDA, PHRI, ASITA, HPI Kabupaten Timor Tengah Selatan , Camat Fatumnasi , Kepala Desa Fatumnasi, Nenas, Nuapain, Kuanoel dan Mutis, Kelompok Sadar Wisata (POKDARWIS), tokoh adat/masyarakat dan wisatawan di Kecamatan Fatumnasi. Pengumpulan data primer dilakukan dengan interview atau wawancara terstruktur dengan menggunakan kuesioner, wawancara mendalam (indepth interview) dengan menggunakan lembar testimoni analisa SWOT.

b. Data Sekunder yaitu data diperoleh untuk mendukung penelitian ini yang meliputi data dari UNWTO, Kemenpar RI, dan Dinas Pariwisata Provinsi NTT.

\subsection{Populasi dan Sampel}

Populasi sekaligus sampel dalam penelitian ini adalah Dinas Pariwisata , BAPPEDA, PHRI, ASITA, HPI Kabupaten Timor Tengah Selatan, Camat Fatumnasi , Kepala DesaFatumnasi, Nenas, Nuapain, Kuanoel dan Mutis , Kelompok Sadar Wisata (POKDARWIS) , tokoh adat/masyarakat sebanyak 30 responden dan wisatawan nusantara dan mancanegara sebanyak 20 orang yang berkunjung ke ODTW di Kecamatan Fatumnasi. Penarikan sampel dilakukan secara purposive sampling sebanyak 50 orang yang terdiri.

\subsection{Defenisi Operasional Variabel}

1. Potensi Wisata adalah hal-hal yang dapat dijadikan daya tarik bagi wisatawan untuk berkunjung yang terdiri dari atraksi alam, budaya dan man made.

2. Sikap masyarakat adalah pendapat yang ditunjukkan oleh warga masyarakat berkaitan dengan perencanaan pengembangan desa wisata khususnya sikap masyarakat dalam mewujudkan sapta pesona.

3. Sapta pesona adalah kondisi ideal yang harus diwujudkan dalam rangka menarik minat wisatawan berkunjung ke suatu 
daerah dengan meningkatkan kesadaran, rasa tanggung jawab segenap lapisan masyarakat yang terdiri dari 7 unsur yaitu aman, tertib, bersih, sejuk, indah, ramah dan kenangan .

4. Atraksi adalah daya tarik dari suatu objek pariwisata atau hasil kesenian dan hasil buatan manusia yang dapat menarik minat wisatawan untuk berkunjung ke destinasi tersebut. Atraksi berkaitan dengan what to see and what to do

5. Aksesibilitas adalah sarana atau infrastuktur menuju ke destinasi termasuk pesanagan rambu-rambu jalan dan lokasi wisata yang dapat memudahkan wisatawan mengujungi destinasi tersebut.

6. Amanities adalah segala fasilitas pendukung yang bisa memenuhi kebutuhan dan keinginan wisatawan selama berada di destinasi seperti pondik wisata, warung makan dan minum serta pelayanan atau hospitality yang diterima oleh wisatawan.

7. Ancillararies adalah lembaga pendukung yang mengurus destinasi tersebut.

\subsection{Teknik Analisa Data
3.6.1 Analisis SWOT (Strengths, Weaknesses, Opportunities, dan Threats)

Analisis SWOT digunakan menganalisis data untuk memperoleh alternatif strategi dalam pengembangan desa di kabupaten Timor Tengah selatan menjadi desa wisata. SWOT merupakan suatu analisis yang dapat dipergunakan untuk merumuskan strategi, yang terdiri atas analisis keunggulan, kelemahan, peluang, dan ancaman yang dihadapi oleh suatuperusahaan untuk mencapai tujuan. Dalam mengembangkan alternatif strategi, dapat dilakukan dengan alat bantu analisis SWOT (Strengths, Weaknesses, Opportunities, Threats) yang didasarkan pada situasi lingkungan internal dan eksternal. Matrik ini mampu menghasilkan empat set kemungkinan strategi berikut ini.

1. Strategi SO (Strengths - Opportunities) yaitu memanfaatkan seluruh kekuatan untuk merebut dan memanfaatkan peluang sebesarbesarnya.

2. Strategi ST (Strengts - Threats) yaitu strategi dalam menggunakan kekuatan yang dimiliki untuk mengatasi ancaman.

3. Strategi WO (Weaknesses - Opportunities), strategi ini diterapkan berdasarkan peluang yang ada dengan cara meminimalkan kelemahan yang ada.

4. Strategi WT (Weakness- Threat), strategi ini didasarkan pada kegiatan yang bersifat defensif dan berusaha meminimalkan kelemahan yang ada serta menghindari ancaman.

\subsubsection{Importance Performance Analysis (IPA)}

Importance-Performance Analysis digunakan untuk memetakan hubungan antara kepentingan dengan kinerja dari masing-masing atribut yang ditawarkan dan kesenjangan antara kinerja dengan harapan dari atribut-atribut tersebut atau untuk mengetahui rasio antara harapan dan kinerja kualitas ODTW yang dilaksanakan pada Desa Fatumnasi, Nenas, Nuapain, Kuanoel dan Mutis di Kecamatan Fatumnasi Kabupaten TTS. Teknik ini dikemukakan pertama kali oleh Martilla dan James dalam artikel mereka "ImportancePerformance Analysis" yang dipublikasikan di Journal of Marketing. Pada teknik ini, responden diminta untuk menilai tingkat kepentingan (harapan) menurut responden dan tingkat kinerja (kenyataan layanan) yang dirasakan.

Untuk menghitung tingkat kesesuaian, digunakan rumus berikut:

$$
\mathrm{Tki}=\frac{\mathrm{Xi}}{\mathrm{Yi}} \times 100 \%
$$

Tki = Tingkat kesesuaian responden

$\mathrm{Xi}=$ Skor total penjumlahan per atribut tingkat kinerja

$\mathrm{Yi}=$ Skor total penjumlahan per atribut tingkat kepentingan

Kemudian, dilakukan pemetaan ke dalam diagram kartesius dimana diagram kartesius merupakan suatu bangun yang dibagi atas empat bagian dan dibatasi oleh dua buah garis yang berpotongan tegak lurus pada titik-titik $(\mathrm{X}, \mathrm{y})$ yang mana $\mathrm{X}$ mewakili tingkat kinerja dan $Y$ mewakili tingkat kepentingan.

\section{PEMBAHASAN}

Kecamatan Fatumnasi Kabupaten Timor Tengah Selatan merupakan salah satu dari 32 kecamatan yang memiliki populasi penduduk sebanyak 6.869 jiwa yang memiliki 5 desa , 13 dusun , $30 \mathrm{RW}$ dan $61 \mathrm{RT}$ dan luas wilayah luas wilayah 194,658 $\mathrm{Km}^{2}$. Secara geografis kecamatan Fatumnasi berada diketinggian 1200-1800 dpl. Secara geonologis wilayah Kecamatan fatumnasi arah utara berbatasan dengan Kabupaten TTU, arah selatan berbatasan dengan Kecamatan Mollo Utara, arah timur dengan Kecamatan Tobudan arah barat dengan Kecamatan Nunbena dan Kabupaten Kupang. Letak wilayah berda pada ketinggian $1200-1800$ dpl dengan suhu rata- 
rata $20^{\circ} \mathrm{C}$ dan beriklim tropis lembab. Luas wilayah Kecamatan Fatumnasi 195,65 km² yang terbagi atas kawasan hutan cagar alam fatumnasi dan kawasan pemukiman penduduk. Kawasan permukiman terbagi atas 5 desa yaitu Desa Fatumnasi, Desa Nenas, Desa Mutis, Desa Kuanoel, dan Desa Nuapin. Luas kecamatan per desa dapat dilihat pada tabel berikut ini :

Tabel 1. Luas dan Ketinggian Wilayah Kecamatan Fatumnasi

\begin{tabular}{|l|c|c|}
\hline Nama Desa & $\begin{array}{c}\text { Luas } \\
\text { Wilayah } \\
\left(\mathbf{K m}^{2} \mathbf{)}\right.\end{array}$ & Ketinggian \\
\hline $\begin{array}{l}\text { Desa } \\
\text { Fatumnasi }\end{array}$ & 34,97 & $1.751 \mathrm{dpl}$ \\
\hline Desa Nenas & 58,57 & $1.285 \mathrm{dpl}$ \\
\hline Desa Nuapin & 55,91 & $1.208 \mathrm{dpl}$ \\
\hline $\begin{array}{l}\text { Desa } \\
\text { Kuanoel }\end{array}$ & 34,24 & $1.543 \mathrm{dpl}$ \\
\hline Desa Mutis & 10,96 & $1.276 \mathrm{dpl}$ \\
\hline Total Luas & $\mathbf{1 9 6 , 6 5}$ & \\
\hline
\end{tabular}

Sumber : Data primer diolah kembali ,2016

4.1 Analisis Sikap Masyarakat Terhadap Rencana Pengembangan Desa Wisata Berikut ini hasil rekapitulasi kecenderungan sikap masyarakat terhadap rencana pengembangan desa wisata sesuai dengan unsur-unsur Sapta Pesona ( Aman, Tertib, Bersih, Sejuk, Indah , Ramah dan Kenangan) di Desa Fatumnasi Kecamatan Fatumnasi Kabupaten Timor Tengah Selatan.

Grafik .1 Prosentase Sikap Masyarakat Desa Fatumnasi terhadap

\section{Rencana Pengembangan Desa Wisata}

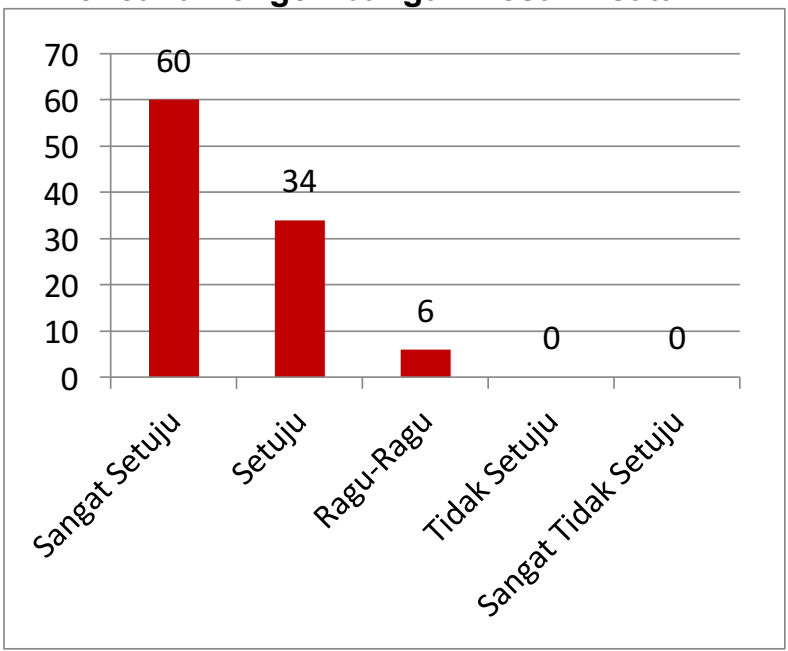

Sumber ; Data olahan, 2016

\subsection{Identifikasi Internal dan Eksternal Pengembangan Desa Wisata Fatumnasi}

Tabel 2. Identifikasi Faktor Internal

\section{\& Eksternal}

\begin{tabular}{|c|c|}
\hline \multirow{2}{*}{ No } & Faktor Internal \\
\hline & Kekuatan (Strenght) \\
\hline S.1 & $\begin{array}{l}\text { Keindahan atraksi wisata berbasis } \\
\text { alam }\end{array}$ \\
\hline S.2 & $\begin{array}{l}\text { Keunikan atraksi wisata berbasis } \\
\text { alam }\end{array}$ \\
\hline S.3 & $\begin{array}{l}\text { Kelestarian atraksi wisata berbasis } \\
\text { alam }\end{array}$ \\
\hline S.4 & $\begin{array}{l}\text { Tersedianya atraksi wisata alam, } \\
\text { budaya dan man made }\end{array}$ \\
\hline S.5 & $\begin{array}{l}\text { Kondisi udara sejuk } 2100 \mathrm{dpl} \text { dengan } \\
\text { suhu } 20^{\circ} \mathrm{C}\end{array}$ \\
\hline S.6 & $\begin{array}{l}\text { Tumbuhnya kegiatan ekonomi kreatif } \\
\text { masyarakat sekitar }\end{array}$ \\
\hline S.7 & $\begin{array}{l}\text { Wilayah pengembangan } \\
\text { Wisata cukup luas } 194,658 \mathrm{Km}^{2} .\end{array}$ \\
\hline S.8 & $\begin{array}{l}\text { Telah terbentuk POKDARWIS Desa } \\
\text { Fatumnasi }\end{array}$ \\
\hline S.9 & $\begin{array}{l}\text { Tersedianya homestay sebanyak } 30 \\
\text { kamar tidur }\end{array}$ \\
\hline S.10 & Pemukiman penduduk belum padat \\
\hline \multirow{2}{*}{ No } & Fakt \\
\hline & Kele \\
\hline W.1 & $\begin{array}{l}\text { Kondisi jalan darat menuju lokasi } \\
\text { rusak berat dan ringan }\end{array}$ \\
\hline W.2 & $\begin{array}{l}\text { Kesiapan penduduk melayani } \\
\text { wisatawan belum sesuai unsur Sapta } \\
\text { Pesona }\end{array}$ \\
\hline W.3 & $\begin{array}{l}\text { Tidak tersedianya Tourist Information } \\
\text { Center (TIC) yang representatif }\end{array}$ \\
\hline W.4 & $\begin{array}{lr}\begin{array}{l}\text { Kurangnya } \\
\text { pengelolaan } \\
\text { masyarakat }\end{array} & \text { pengetahuan } \\
\end{array}$ \\
\hline W.5 & $\begin{array}{l}\text { Ketrampilan berbahasa inggris masih } \\
\text { kurang }\end{array}$ \\
\hline W.6 & $\begin{array}{l}\text { Pengelolaan destinasi masih spatial } \\
\text { dan manajemen keluarga }\end{array}$ \\
\hline W.7 & $\begin{array}{lll}\text { Ketertarikan investor belum ada } \\
\text { untuk mengelola destinasi }\end{array}$ \\
\hline \multirow{2}{*}{ No } & Faktor Eksternal \\
\hline & g (Opportunity) \\
\hline 0.1 & $\begin{array}{l}\text { Adanya kunjungan wisatawan } \\
\text { nusantara dan mancanegara }\end{array}$ \\
\hline 0.2 & $\begin{array}{l}\text { Letaknya strategis dekat dengan } \\
\text { destinasi lainnya di Pulau Timor }\end{array}$ \\
\hline 0.3 & $\begin{array}{l}\text { Adanya komitmen Pemprov NTT } \\
\text { tentang Desa Wisata dalam } \\
\text { RPJMD/P }\end{array}$ \\
\hline 0.4 & $\begin{array}{l}\text { Adanya komitmen pemerintah dalam } \\
\text { menerapkan sustainable tourism } \\
\text { development }\end{array}$ \\
\hline 0.5 & $\begin{array}{l}\text { Adanya komitmen pemerintah dalam } \\
\text { menerapkan community based } \\
\text { tourism }\end{array}$ \\
\hline 0.6 & $\begin{array}{l}\text { Nilai budaya masyarakat Fatumnasi } \\
\text { yang mengakar }\end{array}$ \\
\hline 0.7 & $\begin{array}{l}\text { Terdapat mitra strategis dalam } \\
\text { pengembangan desa wisata }\end{array}$ \\
\hline
\end{tabular}




\begin{tabular}{|c|c|}
\hline \multirow{2}{*}{ No } & Faktor Internal \\
\hline & Ancaman (Threats) \\
\hline T.1 & $\begin{array}{l}\text { Adanya kompetitor dengan desa lain } \\
\text { sebagai desa wisata }\end{array}$ \\
\hline T.2 & $\begin{array}{l}\text { Berubahnya pola pikir dan prilaku } \\
\text { masyarakat terhadap wisatawan }\end{array}$ \\
\hline T.3 & $\begin{array}{l}\text { Berkembangnya era digital tourism } \\
\text { yang tidak dibarengi dengan } \\
\text { kesiapan SDM masyarakat } \\
\text { fatumnasi }\end{array}$ \\
\hline T.4 & $\begin{array}{l}\text { Rusaknya kondisi lingkungan karena } \\
\text { aktivitas wisatawan. }\end{array}$ \\
\hline T.5 & $\begin{array}{lcr}\text { Tergerusnya } & \text { nilai-nilai } & \text { sosial } \\
\text { masyarakat } & \text { karena } & \text { aktivitas } \\
\text { wisatawan } & & \\
\end{array}$ \\
\hline T.6 & $\begin{array}{llr}\text { Terjadinya } & \text { kebocoran } & \text { devisa } \\
\text { (leakage) } & \text { masyarakat } & \text { Desa } \\
\text { Fatumnasi } & \text { karena kurangnya } \\
\text { partisipasi } & \text { masyarakat } & \text { dalam } \\
\text { kegiatan ekonomi } & \end{array}$ \\
\hline
\end{tabular}

Sumber ; Data olahan, 2016

Tabel 3. Alternatif Strategi dan Keterkaitan dengan Faktor Kunci

\begin{tabular}{|c|c|c|}
\hline \multirow{2}{*}{$\begin{array}{l}\mathbf{N} \\
\mathbf{0}\end{array}$} & $\begin{array}{l}\text { Alternatif } \\
\text { Strateqi }\end{array}$ & \multirow{2}{*}{ Keterkaitan } \\
\hline & $\begin{array}{c}\text { Strategi S - } \\
0\end{array}$ & \\
\hline 1 & $\begin{array}{l}\text { Merancang } \\
\text { strategi } \\
\text { pengemban } \\
\text { gan desa } \\
\text { wisata } \\
\text { Fatumnasi } \\
\text { berbasis } \\
\text { masyarakat } \\
\text { yang } \\
\text { berkelanjuta } \\
\mathrm{n} \\
\text { sustainable } \\
\text { community } \\
\text { based } \\
\text { tourism } \\
\text { melalui } \\
\text { model desa } \\
\text { wisata } \\
\text { interaksi } \\
\text { penuh }\end{array}$ & $\begin{array}{l}\text { (S1.S2.S3.S6.S7.S1 } \\
0) \\
(03.04 .05 .06 .07)\end{array}$ \\
\hline 2 & $\begin{array}{l}\text { Menata } \\
\text { daya tarik } \\
\text { wisata yang } \\
\text { ada dengan } \\
\text { baik. }\end{array}$ & $(\mathrm{S} 4 . \mathrm{S} 5 . \mathrm{S} 10)(\mathrm{O} 2 . \mathrm{O} 3)$ \\
\hline 3 & \begin{tabular}{lr}
\multicolumn{2}{l}{ Mempromosi } \\
kan & secara \\
aktif & objek \\
daya & tarik \\
wisata & di
\end{tabular} & $\begin{array}{l}\text { (S4.S5.S8.S9) } \\
(01.02 .03)\end{array}$ \\
\hline
\end{tabular}

\begin{tabular}{|c|c|c|}
\hline & $\begin{array}{l}\text { Desa } \\
\text { Fatumnasi }\end{array}$ & \\
\hline & $\begin{array}{c}\text { Strategi W- } \\
0\end{array}$ & \\
\hline 1 & $\begin{array}{l}\text { Meningkatka } \\
\mathrm{n} \text { peran } \\
\text { PEMDA } \\
\text { Provinsi dan } \\
\text { Kabupaten } \\
\text { dalam } \\
\text { pengemban } \\
\text { gan desa } \\
\text { wisata. }\end{array}$ & $\begin{array}{l}\text { (W1.W2.W3.W4.W5 } \\
\text {.W6.W7) } \\
(01.03 .04)\end{array}$ \\
\hline 2 & $\begin{array}{l}\text { Meningkatka } \\
\mathrm{n} \quad \text { kondisi } \\
\text { akses jalan } \\
\text { menuju desa } \\
\text { wisata } \\
\text { Fatumnasi . }\end{array}$ & $\begin{array}{l}\text { (S1.S2.S7) } \\
\text { (01.02.03) }\end{array}$ \\
\hline 3 & $\begin{array}{l}\text { Meningkatka } \\
\mathrm{n} \text { kualitas } \\
\text { pendidikan } \\
\text { dan } \\
\text { pelatihan } \\
\text { sadar wisata } \\
\text { dan } \\
\text { manajemen } \\
\text { bagi } \\
\text { masyarakat. }\end{array}$ & $\begin{array}{l}\text { (W2.W3.W4.W5.W6) } \\
(\text { O1.O2.03.04.05) }\end{array}$ \\
\hline 4 & $\begin{array}{l}\text { Menjalin } \\
\text { kemitraan } \\
\text { dengan mitra } \\
\text { strategis } \\
\text { dalam } \\
\text { pengemban } \\
\text { gan desa } \\
\text { wisata. }\end{array}$ & $\begin{array}{l}\text { (S4.S5.S8.S9) } \\
(01.02 .03)\end{array}$ \\
\hline & $\begin{array}{c}\text { Strategi S - } \\
\mathbf{T}\end{array}$ & \\
\hline 1 & $\begin{array}{l}\text { Menyusun } \\
\text { paket wisata } \\
\text { desa yang } \\
\text { lebih } \\
\text { bertanggung } \\
\text { jawab } \\
\text { (responsible } \\
\text { tourism) }\end{array}$ & $\begin{array}{l}\text { (S1.S2.S3.S6.S9) } \\
(1 . T 2 . T 4 . T 5)\end{array}$ \\
\hline 2 & $\begin{array}{l}\text { Meningkatka } \\
\mathrm{n} \text { peran serta } \\
\text { masyarakat } \\
\text { dalam } \\
\text { kegiatan } \\
\text { ekonomi } \\
\text { kreatif }\end{array}$ & $\begin{array}{l}\text { (S6.S7.S9.S10) } \\
\text { (T2.T3.T4.T5.T6) }\end{array}$ \\
\hline 3 & $\begin{array}{l}\text { Meningkatka } \\
\mathrm{n} \text { peran dan } \\
\text { fungsi } \\
\text { POKDARWI } \\
\text { S Desa } \\
\text { Fatumnasi }\end{array}$ & $\begin{array}{l}\text { (S4.S8) } \\
\text { (T2.T3.T4.T5.T6) }\end{array}$ \\
\hline
\end{tabular}




\begin{tabular}{|c|c|c|}
\hline & $\underset{T}{\text { Strategi } \mathbf{W}-}$ & \\
\hline 1 & $\begin{array}{l}\text { Mensosialisa } \\
\text { sikan } \\
\text { gerakan } \\
\text { sadar wisata } \\
\text { dengan } \\
\text { program } \\
\text { sapta } \\
\text { pesona }\end{array}$ & $\begin{array}{l}\text { (W2.W4.W5.W6) } \\
\text { (T1.T2.T4.T5) }\end{array}$ \\
\hline 2 & $\begin{array}{l}\text { Membuka } \\
\text { Tourist } \\
\text { Information } \\
\text { Center (TIC) } \\
\text { yang } \\
\text { representatif }\end{array}$ & (W3.W5.W7) (T3.T6) \\
\hline 3 & $\begin{array}{l}\text { Menggalakk } \\
\text { an } \\
\text { masyarakat } \\
\text { melalui } \\
\text { program } \\
\text { Go2H (go to } \\
\text { homestay) } \\
\text { melalui } \\
\text { konsep satu } \\
\text { dusun satu } \\
\text { homestay. }\end{array}$ & $\begin{array}{l}\text { (W4.W5.W7) } \\
\text { (T1.T2.T6) }\end{array}$ \\
\hline
\end{tabular}

Sumber : Data olahan , 2016

\subsection{Importance Performance Analysis}

Analisis IPA ini digunakan untuk memetakan hubungan antara kepentingan dengan kinerja dari masing-masing atribut yang ditawarkan dan kesenjangan antara kinerja dengan harapan dari atribut-atribut tersebut atau untuk mengetahui rasio antara harapan dan kinerja kualitas ODTW yang dilaksanakan pada Desa Fatumnasi, Nenas, Nuapain, Kuanoel dan Mutis di Kecamatan Fatumnasi Kabupaten TTS.

Tabel 4. Perhitungan Tingkat Kesesuaian

\begin{tabular}{|c|c|c|c|c|c|}
\hline \multirow{2}{*}{ No } & $\begin{array}{c}\text { Atribut } \\
\text { Pernyat } \\
\text { aan }\end{array}$ & $\begin{array}{c}\text { Tingka } \\
\mathrm{t} \\
\text { Kepent } \\
\text { ingan }\end{array}$ & $\begin{array}{c}\text { Tin } \\
\text { gka } \\
\mathrm{t} \\
\text { Kin } \\
\text { erja }\end{array}$ & $\begin{array}{c}\text { Tingk } \\
\text { at } \\
\text { Kese } \\
\text { suaia } \\
\mathrm{n}\end{array}$ & $\begin{array}{c}\text { Kriteria } \\
\text { Interpr } \\
\text { etasi } \\
\text { Skor } \\
\text { Tki }\end{array}$ \\
\cline { 2 - 5 } 1. & $\begin{array}{l}\text { Atraksi } \\
\text { Wisata } \\
\text { alam } \\
\text { ala } \\
\text { Kecama } \\
\text { tan } \\
\text { Fatumn } \\
\text { asi }\end{array}$ & 99 & 95 & 96 & $\begin{array}{c}\text { Sangat } \\
\text { Puas }\end{array}$ \\
\hline 2. & $\begin{array}{l}\text { Atraksi } \\
\text { wisata } \\
\text { budaya }\end{array}$ & 98 & 93 & 95 & $\begin{array}{c}\text { Sangat } \\
\text { Puas }\end{array}$ \\
\hline
\end{tabular}

\begin{tabular}{|c|c|c|c|c|c|}
\hline & $\begin{array}{l}\text { masyara } \\
\text { kat } \\
\text { Fatumn } \\
\text { asi }\end{array}$ & & & & \\
\hline 3. & $\begin{array}{l}\text { Atraksi } \\
\text { wisata } \\
\text { man } \\
\text { made } \\
\text { masyara } \\
\text { kat } \\
\text { Fatumn } \\
\text { asi }\end{array}$ & 97 & 85 & 87 & $\begin{array}{c}\text { Sangat } \\
\text { Puas }\end{array}$ \\
\hline 4. & $\begin{array}{l}\text { Kondisi } \\
\text { jalan di } \\
\text { Kecama } \\
\text { tan } \\
\text { Fatumn } \\
\text { asi }\end{array}$ & 98 & 55 & 56 & $\begin{array}{c}\text { Cukup } \\
\text { Puas }\end{array}$ \\
\hline 5. & $\begin{array}{l}\text { Penyedi } \\
\text { aan } \\
\text { sarana } \\
\text { transpor } \\
\text { tasi ; } \\
\text { mobil, } \\
\text { ojek dll }\end{array}$ & 95 & 74 & 78 & Puas \\
\hline 6. & $\begin{array}{l}\text { Rambu- } \\
\text { rambu } \\
\text { lokasi } \\
\text { wisata }\end{array}$ & 96 & 78 & 81 & $\begin{array}{c}\text { Sangat } \\
\text { Puas }\end{array}$ \\
\hline 7. & $\begin{array}{l}\text { Homest } \\
\text { ay atau } \\
\text { pondok } \\
\text { wisata }\end{array}$ & 98 & 85 & 87 & $\begin{array}{c}\text { Sangat } \\
\text { Puas }\end{array}$ \\
\hline 8. & $\begin{array}{l}\text { Warung } \\
\text { makan } \\
\text { dan } \\
\text { minum }\end{array}$ & 93 & 49 & 53 & $\begin{array}{c}\text { Cukup } \\
\text { Puas }\end{array}$ \\
\hline 9. & $\begin{array}{l}\text { Mutu } \\
\text { pelayan } \\
\text { an } \\
\text { amenitie } \\
\text { s di } \\
\text { Fatumn } \\
\text { asi }\end{array}$ & 96 & 65 & 68 & Puas \\
\hline 10. & $\begin{array}{l}\text { Tourist } \\
\text { Informat } \\
\text { ion } \\
\text { Centre } \\
\text { (TIC) }\end{array}$ & 94 & 67 & 71 & Puas \\
\hline 11. & $\begin{array}{l}\text { Souveni } \\
r \text { tenun } \\
\text { kuliner } \\
\text { dan } \\
\text { kerajina } \\
\mathrm{n} \text { tangan }\end{array}$ & 93 & 66 & 71 & Puas \\
\hline 12. & $\begin{array}{l}\text { Kelomp } \\
\text { ok } \\
\text { Sadar } \\
\text { Wisata } \\
\text { Fatumn }\end{array}$ & 98 & 78 & 79 & Puas \\
\hline
\end{tabular}




\begin{tabular}{|c|l|l|l|l|l|}
\hline & asi & & & & \\
\hline$\Sigma$ & 1.155 & 890 & & \\
\hline
\end{tabular}

Untuk menghitung tingkat kesesuaian, digunakan rumus berikut :

$$
\begin{aligned}
\mathrm{Tki} & =\frac{\mathrm{Xi}}{\mathrm{Yi}} \times 100 \% \\
\text { Tki } & =\frac{\mathbf{8 9 0}}{1.155} \times 100 \%=\mathbf{7 7 \%} \\
& =77 \%
\end{aligned}
$$

\begin{abstract}
Berdasarkan hasil perhitungan Importance-Performance Analysis maka dari tingkat kesesuaian diatas diperoleh nilai kesesuaian antara penilaian kepentingan dan harapan wisatawan terhadap kualitas obyek daerah tujuan wisata di Kecamatan Fatumnasi sebesar $77 \%$. Hal ini berarti bahwa persepsi atau penilaian wisatawan termasuk dalam kriteria puas.

Setelah mengetahui nilai rata-rata tiap atribut tingkat kepentingan dan kinerja serta rata-rata keseluruhan atribut maka selanjutnya nilai rata-rata dan atribut pernyataan dimasukan kedalam diagram kartesius empat kuadran sehingga dapat diketahui atributatribut mana yang mempengaruhi penilaian wisatawan pada obyek daerah tujuan wisata di Kecamatan Fatumnasi Kabupaten Timor Tengah Selatan dapat diuraikan berikut ini :
\end{abstract}

Gambar 1. Diagram Kartesius Perhitungan Tingkat Kesesuaian

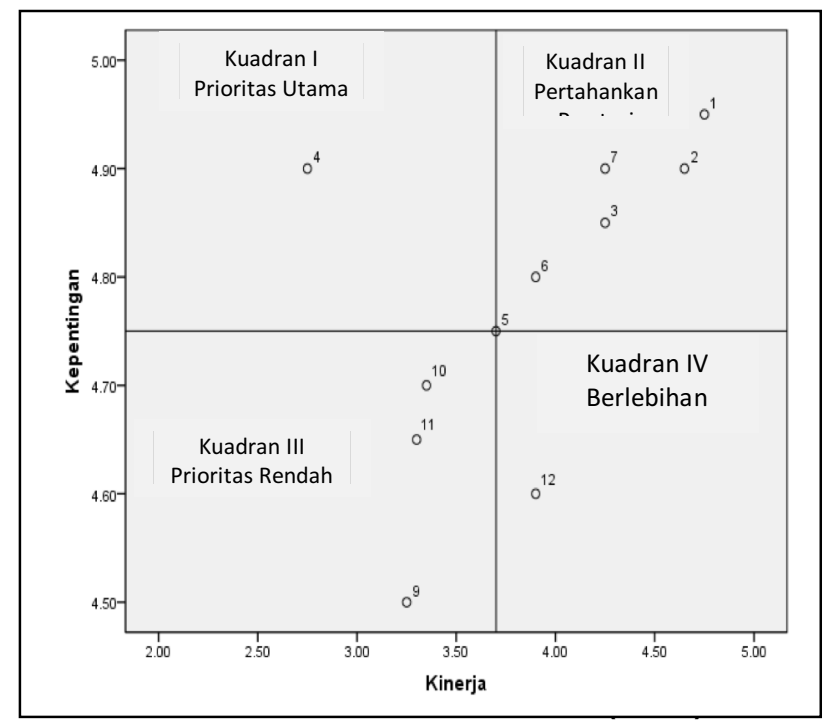

Berdasarkan diagram kartesius diatas, maka masing-masing kuadran akan dijelaskan sebagai berikut :

\section{Kuadran I}

Pada kuadran ini terdapat satu atribut yang masuk didalamnya yakni atribut nomor 4 atau atribut aksesibilitas tentang kondisi jalan . Atribut ini dianggap priortias utama dan penting oleh wisatawan tetapi pada kenyataan kualitas aksesibilitas jalan belum sesuai dengan harapan sehingga wisatawan mempersepikan atribut layanan ini belum memuaskan, relatif rendah dan wisatawan merasa kecewa sehingga kondisi jalan harus segera di perbaiki

\section{Kuadran II}

Pada kuadran ini terdapat enam atribut yang masuk didalamnya yakni atribut nomor 1 , 2, 3, 5,6, dan 7 atau atribut atraksi wisata alam, wisata budaya, buatan manusia, sarana transportasi, rambu lokasi wisata dan homestay . Atribut-atribut ini pada kenyataan layanannya sudah sesuai dengan harapan wisatawan sehingga wisatawan mempersepsikan keenam layanan ini sudah memuaskan dan harus tetap dipertahankan dan ditingkatkan melalui penerapan model desa wisata interaksi penuh.

\section{Kuadran III}

Pada kuadran ini terdapat empat atribut yang masuk didalamnya yakni atribut nomor $8,9,10$, dan 11 atau atribut warung mamin, mutu pelayanan amenitas, tourist information center, dan kios souvenir. Atribut-atribut ini dianggap kurang penting dan pada kenyataannya tidak terlalu istimewa sehingga dipersepsikan kepuasan terhadap kenyataan layanan relatif rendah. Akan tetapi peningkatan kinerja keempat atribut ini dapat dipertimbangkan untuk di lakukan dengan baik walaupun atribut tersebut memberikan dampak yang kecil bagi pengembangan desa wisata di Desa Fatumnasi .

\section{Kuadran IV}

Pada kuadran ini terdapat hanya satu atribut yang masuk didalamnya yakni atribut nomor 12 atau atribut kelompok sadar wisata (Pokdarwis). Atribut Pokdarwis ini dianggap kurang penting dan dirasakan terlalu berlebihan oleh wisatawan sehingga dipersepsikan kepuasan wisatawan terhadap keberadaan layanan Pokdarwis dianggap relatif cukup. Atribut Pokdarwis dapat dikurangi masyarakat atau anggota yang terlibat didalamnya agar lebih ramping organisasinya tetapi dapat ditingkatkan kualitas anggotanya melalui pelatihan dan nencembangan pengelolan manajemen ( Kuadran IV wisatawan yang berkunjung $\mathrm{k} \iota$ Berlebihan si . 


\section{PENUTUP}

\subsection{Kesimpulan}

Berdasarkan hasil penelitian, hasil analisis dan pembahasan yang telah dikemukakan maka dapat ditarik kesimpulan sebagai berikut

1. Kecenderungan sikap masyarakat sebesar $60 \%$ menyatakan sangat setuju untuk menjadikan Desa Fatumnasi sebagai desa wisata, sebesar $36 \%$ menyatakan setuju dan sebesar $4 \%$ masih menyatakan ragu-ragu untuk mendukung program desa wisata .

2. Motivasi wisatawan nusantara dan mancanegara berwisata ke wilayah Kecamatan Fatumnasi karena tersedianya atraksi wisata alam pegunungan dengan cuaca sekitar $20^{\circ} \mathrm{C}$ dan terdapat beragam budaya seperti tarian dan kuliner lokal (jagung bose dan sambal luat ) dari Suku Dawan yang mendiami wilayah tersebut.

3. Berdasarkan hasil perhitungan Importance-Performance Analysis maka dari tingkat kesesuaian diatas diperoleh nilai kesesuaian antara penilaian kepentingan dan harapan wisatawan terhadap kualitas obyek daerah tujuan wisata di Kecamatan Fatumnasi sebesar $77 \%$. Hal ini berarti bahwa persepsi atau penilaian wisatawan termasuk dalam kriteria puas.

4. Tingkat kesesuaian paling besar adalah pada item penilaian atraksi wisata alam Kecamatan Fatumnasi sebesar $96 \%$ yang berarti bahwa atraksi yang disajikan dalam bentuk wisata alam gunung, pemandangan, udara yang sejuk, hutan lindung dapat sesuai dengan harapan dan tingkat kenyataan yang dirasakan wisatawan.

\subsection{Saran-Saran}

1. Perbaikan sarana jalan ke wilayah Kecamatan Fatumnasi melalui kerjasama lintas sektor di tingkat kabupaten dan tingkat provinsi .

2. Pengembangan desa wisata di Desa Fatumnasi hendaknya dilakukan melalui model intraksi penuh artinya melalui konsep sustainable community based tourism dengan mengambil lokasi di Desa Fatumnasi sebagai pilot project.

3. Pembuatan destination image sebagai brand awareness bagi wisatawan yang akan berkunjung ke Desa Fatumnasi

4. Pihak BPW disarankan untuk selalu aktif mempromosikan kegiatan wisata di Desa Fatumnasi baik secara online dan offline

\section{DAFTAR PUSTAKA}

Denzin, N.K. dan Lincoln Y. 2009. Handbook of Qualitative Research. Yogyakarta:

Pustaka Pelajar.

Murphy, P.E. 1985. Tourism: A Community Approach. London: Methuen.

Nurhidayati, Sri Endah. Community Based Tourism (CBT) sebagai Pendekatan Pembangunan Pariwisata Berkelanjutan. Surabaya : Airlangga press.

Nuryanti, Wiendu. 1993. Concept, Perspective and Challenges dalam makalah bagian dari Laporan Konferensi Internasional Mengenai Pariwisata Budaya. Gadjah Mada University Press. Yogyakarta.

Page, Stephen J dan Getz, Don. 1997. The Business of Rural Tourism (International

Perspective). International Thomson Business Press, London.

Rangkuti, Freddy. 2006.Analisis SWOT Teknik Membedah Kasus Bisnis. Penerbit PT. Gramedia Pustaka Utama, Jakarta.

REST. 1997. Community Based Tourism Handbook. Bangkok: The Responsible Ecological Social Tours (REST) Projects. hhtp://www.rest.or.th/studytours/medias/c hapter1eng.pdf.

Suwantoro, Gamal. 2005. Dasar-Dasar Pariwisata. Yogyakarta : Andi Offset

Suansri, Potjana. 2003. Community Based Tourism Handbook. Thailand : REST Project.

Timothy, D.J. 1999. Participatory Planning a View of Tourism in Indonesia. Annuals Review of Tourism Research.

Undang-Undang Republik Indonesia Nomor 10 Tahun 2009 Tentang Kepariwisataan.

UNWTO, 2002, Rural Tourism, Experiences and Perspective, UNWTO, Madrid

Yaman, Amat Ramsa \& A. Mohd. 2004. Community -based Ecotourism: New Proposition for Sustainable Development and Environment Conservation in Malaysia. Journal of Applied Sciences.

Yoeti, Oka. 1997. Perencanaan dan Pengembangan Pariwisata. Jakarta : PT Pradnya Paramita.

Yoeti, Oka. A. 2008. Perencanaan dan Pengembangan Pariwisata, PT. Pradnya Paramita, Jakarta 